\title{
A música como forma expressão da realidade de adolescentes em vulnerabilidade
} social

\section{Music as an expression of the reality of socially vulnerable adolescents vulnerability \\ La música como forma de expresión de la realidad de adolescentes en vulnerabilidad social}

Recebido: $28 / 02 / 2018$

Aprovado: $30 / 08 / 2018$

Publicado: 27/09/2018

\author{
Andrea Ruzzi-Pereira1 \\ Larissa Nascimento Marques ${ }^{2}$ \\ Mariana Melo Parreira ${ }^{3}$
}

Este trabalho tem como objetivo descrever a experiência em estágio de terapia ocupacional com adolescentes do sexo feminino em tratamento para problemas relacionados ao uso de álcool e outras drogas, na construção coletiva de um rap. A metodologia foi pautada nos preceitos da clínica ampliada, saúde mental, atenção psicossocial, e projeto de vida. 0 grupo foi composto por seis usuárias, com 28 intervenções, entre março e julho de 2013 mediadas por uma docente, e duas estagiárias. A produção musical destacou a violência contra a mulher; o uso de drogas; a criminalidade; e, a necessidade de um fator de proteção, a espiritualidade/religiosidade. A atuação da terapia ocupacional com estas adolescentes propiciou um espaço de trocas afetivas e de experiências positivas.

Descritores: Adolescente; Vulnerabilidade social; Música.

This study aims to describe the experience from an occupational therapy internship with female adolescents being treated for problems related to the use of alcohol and other drugs in the collective construction of a rap song. The methodology was based on expanded clinical practice concepts, mental health, psychosocial attention and life projects. The group was made up of six female users, with 28 interventions from March to July 2013, with the mediation of a professor and two interns. The musical production highlighted: violence against women; the use of drugs; criminality; and the need for a protective factor, namely, spirituality/religiosity. The actions of the occupational therapist with these adolescents transformed the meetings in spaces for affective exchanges and positive experiences.

Descriptors: Adolescent; Social vulnerability; Music.

Este trabajo tiene como objetivo describir la experiencia en prácticas de terapia ocupacional con adolescentes del sexo femenino en tratamiento para problemas relacionados al uso de alcohol y otras drogas, en la construcción colectiva de un rap. La metodología fue pautada a partir de los preceptos de la clínica ampliada, salud mental, atención psicosocial y proyecto de vida. El grupo fue compuesto por seis usuarias, con 28 intervenciones, entre marzo y julio de 2013 mediadas por una docente y dos practicantes. La producción musical destacó la violencia contra la mujer; el uso de drogas; la criminalidad y la necesidad de un factor de protección, la espiritualidad/religiosidad. La actuación de la terapia ocupacional con estas adolescentes propició un espacio de intercambios afectivos y de experiencias positivas.

Descriptores: Adolescente; Vulnerabilidad social; Música.

1. Terapeuta Ocupacional. Especialista em Saúde Pública e Saúde Mental. Mestre e Doutora em Ciências Médicas. Professor Adjunto do Departamento de Terapia Ocupacional da Universidade Federal do Triângulo Mineiro (UFTM), Uberaba, MG, Brasil. ORCID: 0000-0001-6014-0468 E-mail: andrea.pereira@uftm.edu.br

2. Terapeuta Ocupacional. Especialista em Tratamento Neuroevolutivo (Conceito Bobath). Especialista em Tecnologia Assistiva, Uberaba, MG, Brasil. ORCID: 0000-0001-7313-426X E-mail: larissatouftm@hotmail.com

3. Terapeuta ocupacional. Secretaria de Estado de Segurança Pública, Uberaba, MG, Brasil. ORCID: 0000-0002-7761-9288

E-mail: marianamelop.to@hotmail.com 


\section{INTRODUÇÃO}

Cegundo o Estatuto da Criança e do Adolescente ${ }^{1}, \quad$ a $\quad$ adolescência

- compreende a faixa etária dos 12 aos 18 anos de idade, sendo este um período em que ocorrem mudanças fisiológicas, psicossociais, físicas e sexuais, e que marca a transição da infância para a vida adulta $^{2}$. É nessa fase da vida em que ocorre a formação de uma identidade social, sendo esta determinada pela cultura e contexto social no qual o adolescente se insere ${ }^{2}$.

No entanto, quando a adolescência é permeada por contradições e conflitos ou é atravessada por vivências violentas, tornamse preocupante as repercussões negativas para a saúde física e mental do indivíduo, comprometendo a construção de seus projetos de vida.

Esta fase pode ser marcada por muitas dúvidas, inseguranças e conflitos internos e por isso os jovens são considerados como um segmento vulnerável em todas as sociedades do mundo globalizado e pequenas mudanças podem impactar toda a vida ${ }^{3}$. É, também, uma época de descoberta e experimentação, quando várias pessoas usam o álcool e as outras drogas pela primeira $\mathrm{vez}^{4}$, com a possiblidade de continuar o consumo dessas substâncias ao longo da vida ou não.

0 adolescente pode estar exposto a vários fatores que o torna mais vulnerável ao adoecimento e ao uso de drogas. A vulnerabilidade refere-se à susceptibilidade individual ou familiar de desenvolver um distúrbio ou desadaptação diante de indicadores de risco ${ }^{5}$. Como fatores de vulnerabilidades aos adolescentes, pode-se destacar os riscos inerentes a dinâmica familiar, como os problemas relacionados ao alcoolismo e violência; o lugar de moradia; a disponibilidade dos espaços para lazer; os riscos relacionados à forma de repressão policial, às atividades do tráfico de drogas e à violência urbana ${ }^{6}$.

A preocupação com o uso de drogas tem crescido a partir da década de 1960, devido à forma como as pessoas passaram a consumir tais substâncias e o aumento do consumo pelos adolescentes ${ }^{7}$. Assim, o uso de álcool e outras drogas tem se constituído como um problema de saúde pública mundial, principalmente pelo uso indistinto por pessoas de todas as idades, sexo e classes sociais.

Mas para alguns grupos específicos, como os adolescentes, o cuidado é maior devido aos anos eventualmente perdidos ou riscos a que eles se expõem ${ }^{8}$, e tem sido apontado como uma das principais causas que desencadeiam situações de vulnerabilidade na adolescência, a exemplo dos suicídios, violência, gravidez não planejada, prostituição e a transmissão de doenças por via sexual, o que justifica a realização de estudos e intervenções sobre a temática com essas pessoas.

Este trabalho tem como objetivo descrever a experiência em estágio de terapia ocupacional com adolescentes do sexo feminino em tratamento para problemas relacionados ao uso de álcool e outras drogas, na construção coletiva de um rap.

\section{MÉTODO}

0 trabalho desenvolvido com as adolescentes foi pautado nos preceitos da clínica ampliada, saúde mental e atenção psicossocial. Apresenta ações desenvolvidas em estágio supervisionado do curso de terapia ocupacional do $8^{o}$ período da Universidade Federal do Triângulo Mineiro (UFTM), realizado entre março e julho de 2013, no Instituto Municipal sobre Drogas de Uberaba, que à época atendia adolescentes do sexo feminino com idade entre 12 e 18 anos, e que tinham problemas relacionados com álcool e outras drogas e que estavam em estado de vulnerabilidade social.

As intervenções aconteceram duas vezes na semana, eram mediadas por uma docente e duas estagiárias. 0 grupo de adolescentes era composto, em média por seis usuárias. As considerações das participantes sobre os grupos foram transcritas pelas estagiárias em um caderno de registros e, posteriormente, discutidas com a supervisora, sendo aqui apresentadas a partir de uma análise de abordagem qualitativa descritiva.

0 desenvolvimento deste estudo seguiu todas as normas éticas norteadoras dos trabalhos que envolvem seres humanos, 
sendo aprovado pelo Comitê de Ética em Pesquisa da Universidade Federal do Triângulo Mineiro, sob o número 2303/2013.

\section{RESULTADOS}

Durante a atividade com as adolescentes foram discutidos alguns temas como: sexualidade; projeto de vida; cuidado consigo e com o outro; família; tipos de violência, e formas de enfrentamento. Foi utilizado para o processo terapêutico ocupacional estratégias como teatro, jogos lúdicos, filmes, músicas, confecção de cartazes, atividade para o cuidado da imagem e confecção de acessórios femininos artesanais com materiais de baixo custo.

Foi discutido com as adolescentes um modo de trazerem esses temas agrupados, de forma que representasse a realidade vivida por elas, que escolheram elaborar a letra de um rap, que intitularam de "Manos da Vila" e nomearam o próprio grupo como "As guerreiras".

A construção coletiva envolveu todas as participantes de maneira intensa, durante seis semanas, levando-as a reflexão do contexto de cada participante, que se revelou um contexto coletivo. Após a elaboração da letra, fizeram a melodia e a produção de um clipe como protagonistas e cantoras. A referida produção se apresenta a seguir.

\section{0 rap Manos da Vila}

Hoje em dia os manos da vila

Estão fugindo da polícia

Trocando seus sonhos por nada

E entrando no mundo do crime por arma

Drogas, show, mulheres, dinheiro fácil

Pra morte é só um passo, passo, passo...

Estão fugindo da polícia

Entrando nesse mundo de crime e violência

Meu Deus, do que vale essa vida?

Cadê a nossa crença?

Tudo começa com um cigarro de baseado

Depois cocaína, crack, roubo, miséria, dinheiro roubado

Muito jovem trocando sua vida pelo crack

Matando pessoas, 157 é mato.

A nossa vida passa por vários episódios
Roubo, homicídio, crime, violência

$A$ vida parece ser bela

E ai doidão olha pela janela

$E$ você verá o sofrimento que vem dela, dela, dela...

\section{Estão fugindo da polícia}

Entrando nesse mundo de crime e violência

Meu Deus, do que vale essa vida?

Cadê a nossa crença?

Muitos homens pensam que as mulheres são um saco de pancada

Socos na barriga, chutes na cabeça,

Nossa, que tristeza!!!

Eu me lembro do dia que ele me trancou dentro do banheiro, puxou meu cabelo e me chutava como se estivesse batendo num homem. Muitas das vezes minha menininha via ele me batendo e pedia para parar: Papai não faça isso com a minha mamãe.

\section{Estão fugindo da polícia}

Entrando nesse mundo de crime e violência

Meu Deus, do que vale essa vida?

Cadê a nossa crença?

Não podemos aceitar essa situação

O importante é ter Deus no coração!

\section{DISCUSSÃO}

Nas letras de rap, os autores narram suas experiências de vida e o cotidiano de suas comunidades, viabilizando com isto um processo de identificação por aqueles que possuem a mesma realidade, onde se pode encontrar temas como privação financeira, preconceito social e racial. É uma importante forma de expressão, servindo como porta voz da realidade vivenciada por esta população ${ }^{9}$.

Assim como em outro trabalho ${ }^{10}$, a letra escrita pelas "Guerreiras" revelou semelhanças em suas experiências cotidianas. Ao falar do outro, em "Os Manos da Vila", ficou evidente a dificuldade das meninas em falar diretamente sobre si. Em um trecho, elas mostram uma relação entre a adolescência e a criminalidade, sendo que no seu cotidiano algumas delas já cometeram atos infracionais e se envolveram com o tráfico de drogas. 
Cometer infração é uma forma que alguns adolescentes utilizam para sair de sua invisibilidade, buscando conquistar uma posição de respeito em sua comunidade9. Apesar do aumento do número de adolescentes envolvidas em atos infracionais, esta população continua sendo mais vítima do que autora da violência. Devido ao peculiar estágio de desenvolvimento em que se encontra, apresenta mais vulnerabilidade a diversas situações de risco, sendo agravado quanto maior a exposição as desigualdades sociais ${ }^{11}$.

0 trecho "entrando no mundo do crime por arma [...] dinheiro fácil" menciona os motivos que levariam os adolescentes a cometerem um ato infracional. Estudos apontam que os principais riscos para isto são o consumo de drogas, os tipos de lazer, o grupo de amigos, a autoestima, o reconhecimento dos limites entre o certo e o errado, ser vítima de violência e os vínculos com relação à escola12,13.

Os limites entre ser ou não ser autor de um ato infracional são tênues e podem ser ultrapassados a qualquer momento por um adolescente, considerando esta vulnerabilidade como uma característica desta fase da vida. Além disto, a baixa condição socioeconômica é um importante fator de risco para o uso de drogas na adolescência ${ }^{14}$. As adolescentes também expressam algumas consequências negativas da criminalidade, como a não realização de seus sonhos e a morte precoce, por meio de trechos como: "trocando seus sonhos por nada e pra morte é só um passo".

Em "Tudo começa com um cigarro de baseado, depois cocaína, crack", as adolescentes dão a ideia de aumento no consumo de drogas. Iniciam o uso com a droga considerada por elas mais leve, passando para cocaína, crack. Adolescentes em certo estágio de consumo de drogas não necessariamente irão usar outras drogas, ressaltando que não haveria certa sequência de gravidade do risco de consumo de substâncias mais leves para as mais nocivas ${ }^{15}$. Contudo, existe em nossa sociedade a cultura de que há drogas menos nocivas e mais fracas e, principalmente entre os adolescentes, de que o álcool não é considerado uma droga e tem seu consumo visto como algo normal e aceitável ${ }^{15}$.

Uma pesquisa ${ }^{17}$ reforça a necessidade de que as políticas públicas existentes, principalmente em relação ao álcool, sejam realmente efetivadas e que haja esforços políticos para um trabalho com a população na busca da compreensão de que o álcool é uma droga e, como tal, o uso abusivo pode levar a consequências danosas; de que não há quantidade segura para o uso do álcool por adolescentes e que ele é a droga de acesso às outras substâncias, mas por si só já é a droga que mais traz prejuízos físicos, psíquicos e sociais.

As participantes abordam as consequências do abuso de drogas, que pode levar a execução de roubo e de homicídio, e a se afastarem dos estudos e de familiares. 0 uso de drogas pode acarretar negativamente a vida social do adolescente, prejudicando o desempenho relacional, na escola e, muitas vezes com a lei ${ }^{16}$. Dentre as participantes, todas haviam parado os estudos nas primeiras séries do ensino fundamental 1 , sem planos de retorno.

A música aponta um envolvimento ambíguo das adolescentes com a violência. Ora desempenham papel de vítimas, destacando a violência contra a mulher, e ora são as agressoras. 0 tema violência contra a mulher teve destaque durante a elaboração da letra da música, tendo em vista fazer parte da realidade de todas elas. Foi decidido pelo grupo que o trecho da música sobre esse tema deveria se constituir por um depoimento real de uma delas, que estava grávida pela terceira vez à época do estudo, apontado no trecho entre "eu me lembro do dia que ele me trancou dentro do banheiro [até] papai não faça isso com a minha mamãe".

A violência física na vida adulta vinda de um parceiro atinge cerca de $20 \%$ a $50 \%$ das mulheres ao redor do mundo ao menos uma vez na vida e esses episódios de violência são repetitivos e tendem a se tornar progressivamente mais graves, inclusive durante o período da gestação ${ }^{17}$. Esse fato foi consoante com a situação encontrada, chegando algumas adolescentes a sofrerem aborto após a agressão. 
0 refrão do rap traz "Deus" e a necessidade de uma crença e apresentam um fator de proteção, a religiosidade (ou espiritualidade). A religiosidade melhora os índices de recuperação para pessoas em tratamento de drogas e diminuição dos índices de recaída; e, a religião promove a abstinência do consumo de drogas e oferece recursos sociais de reestruturação, valorização das potencialidades individuais e coesão de grupo ${ }^{18}$.

Durante as intervenções, as adolescentes se mostraram participativas, expressando suas opiniões e ideias. 0 terapeuta ocupacional é um profissional que viabiliza a construção de espaços potentes que se configurem canais de expressão dos adolescentes, de maneira a fornecer-lhes alternativas de expressar suas angústias, diante do sofrimento gerado pelo processo de exclusão social. Assim, uma vez que o indivíduo percebe o espaço de intervenção como um espaço possível de (re) construir sua existência no mundo, ele se mostra aberto a aprender novas estratégias de ação e expressão ${ }^{19}$.

\section{CONCLUSÃO}

A composição da letra do rap criado pelas adolescentes condiz com a realidade vivenciada por elas, porém elas se colocaram como observadoras dos fatos, e optaram por narrar a história em $3^{\text {a }}$ pessoa. 0 rap destaca a violência contra a mulher, o uso de álcool $\mathrm{e}$ outras drogas e a criminalidade. Também há destaque para um fator de proteção, a espiritualidade e ou religiosidade.

A atuação do terapeuta ocupacional com as adolescentes, propiciou um espaço de troca que otimizou a relação entre o grupo. E, o recurso musical possibilitou às adolescentes uma livre expressão de sua própria realidade. Apesar disso, essa população não pode mais ser acolhida em instituições como aquela em que o estágio se desenvolveu, devido ao cumprimento das políticas públicas de atenção ao adolescente usuário de substâncias psicoativas.

Os adolescentes são a clientela de menor adesão nos tratamentos ambulatoriais para álcool e outras drogas e, possivelmente, usar recursos significativos para a realidade deles, ajuda na adesão ao tratamento, e em melhores resultados.

Reconhece-se como limites desse relato a divulgação de apenas uma das estratégias utilizadas durante o estágio. Desta forma se faz necessário o olhar para adolescentes com o mesmo problema, mas que residam em comunidades rurais ou centros urbanos maiores, que compartilhem dessa realidade.

\section{REFERÊNCIAS}

1. Presidência da República (Brasil). Lei $\mathrm{n}^{0}$ 8.069, de 13 de julho de 1990. Dispõe sobre o Estatuto da Criança e do Adolescente e dá outras providências [Internet]. D.O.U., Brasília, DF, 16 jul 1990 [citado em 30 jan 2018]. Disponível em: http://www.planalto.gov.br/ccivil_03/leis/L 8069.htm

2. Machado NG, Moura ERF, Conceição MAV, Guedes TG. Uso de drogas e saúde sexual de adolescentes. Rev Enferm UERJ. [Internet]. 2010 [citado em 30 jan 2018]; 18(2):284-90. Disponível em: http://www.facenf.uerj.br/v18n2/v18n2a20. pdf

3. Murphy K, Sahm L, McCarthy S, Lambert S, Byrne S. Substance use in young persons in Ireland: a systematic review. Addict Behav. [Internet]. 2013 [citado em 30 jan 2018]; 38(8):2392-401. Disponível em: https://www.sciencedirect.com/science/arti cle/pii/S0306460313000889?via\%3Dihub

4. Smyth BP, Kelly A, Cox G. Decline in age of drinking onset in Ireland, gender and per capita alcohol consumption. Alcohol. [Internet]. 2011 [citado em 30 jan 2018]; 46(4):478-84. Disponível em: https://academic.oup.com/alcalc/article/46 /4/478/109588

5. Veselska Z, Geckova AM, Orosova O, Gajdosova B, van Dijk JP, Reijneveld SA. Selfesteem and resilience: the connection with risky behavior among adolescents. Addict Behav. [Internet]. 2009 [citado em 30 jan 2018]; 34(3):287-91. Disponível em: https://www.sciencedirect.com/science/arti cle/pii/S0306460308003134?via\%3Dihub 
6. Trucco EM, Colder CR, Wieczorek WF. Vulnerability to peer influence: a moderated mediation study of early adolescent alcohol use initiation. Addict Behav. [Internet]. 2011[citado em 30 jan 2018]; 36(7):729-36. Disponível em: https://www.ncbi.nlm.nih.gov/pmc/articles/ PMC3088763/pdf/nihms285576

7. Soares LCO, Ruzzi-Pereira A, Pereira PE, Cavalcanti A, Andrade VS. Papéis ocupacionais de mulheres que fazem uso abusivo de substâncias psicoativas. Rev Ter Ocup. [Internet]. 2014 [citado em 30 jan 2018]; 24(3):199-207. Disponível em: http://www.revistas.usp.br/rto/article/view $/ 52375$

8. Benjet C, Borges G, Méndez E, Casanova L, Medina-Mora ME. Adolescent alcohol use and alcohol use disorders in Mexico City. Drug Alcohol Depend. [Internet]. 2014 [citado em 30 jan 2018]; 136:43-50. Disponível em: http://www.drugandalcoholdependence.com /article/S0376-8716(13)00522-X/fulltext

9. Silva CYG. Nas batidas do rap, nas entrelinhas dos versos: uma reflexão winnicotiana sobre o amadurecimento juvenil [Internet]. [dissertação]. São Paulo: Universidade de São Paulo, Instituto de Psicologia; 2016 [citado em 30 jan 2018]. Disponível em: http://www.teses.usp.br/teses/disponiveis/ 47/47133/tde-16082016-105944/pt-br.php 10. Bolzani B, Bittar CML. Oficinas de artes visuais para adolescentes em situação de risco social: uma possibilidade para ações em promoção de saúde. Adolesc Saúde [Internet]. 2017 [citado em 30 jan 2018]; 14(1):7-13. Disponível em: http://www.adolescenciaesaude.com/detalh e_artigo.asp?id=630

11. Silva ERA, Oliveira RM. Os Jovens adolescentes no Brasil: a situação socioeconômica, a violência e o sistema de justiça juvenil. In: Silva, ERA, Macedo, DMB. Dimensões da experiência juvenil brasileira e novos desafios às políticas públicas. Brasília, DF: IPEA; 2016 [citado em 30 jan 2018]. Disponível em: http://www.ipea.gov.br/agencia/images/sto ries/PDFs/livros/livros/livro_dimensoes_mi olo_cap10.pdf
12. Larrosa SL, Palomo JLR-A. Factores de riesgo y de protección en el consumo de drogas en adolescentes y diferencias según edad y sexo. Psicothema [Internet]. 2010 [citado em 30 jan 2018]; 22(4):568-73. Disponível em: http://www.psicothema.com/pdf/3768.pdf 13. Zehe JM, Colder CR. A latent growth curve analysis of alcohol-use specific parenting and adolescent alcohol use. Addict Behav. [Internet]. 2014 [citado em 30 jan 2018]; 39(12):1701-5. Disponível em: https://www.sciencedirect.com/science/arti cle/pii/S030646031400152X?via\%3Dihub

14. Hurd YL, Michaelides M, Miller ML, JutrasAswad D. Trajectory of adolescent cannabis use on addiction vulnerability. Neuropharmacology [Internet]. 2014 [citado em 30 jan 2018]; 76 Pt B:416-24. Disponível em:

http://www.ncbi.nlm.nih.gov/pmc/articles/ PMC3858398

15. Ruzzi-Pereira A. Prevalência do uso de álcool e outras drogas entre escolares da rede pública de ensino de Uberaba - MG: fatores de risco e de proteção [Internet]. [Tese]. Ribeirão Preto: Faculdade de Medicina de Ribeirão Preto; 2015 [citado em 30 jan 2018]. Disponível em: http://www.teses.usp.br/teses/disponiveis/ 17/17139/tde-28072015-101016/

16. Salas-Wright CP, Hernandez L, Maynard BR, Saltzman LY, Vaughn MG. Alcohol use among hispanic early adolescents in the United States: an examination of behavioral risk and protective profiles. Subst Use Misuse. [Internet]. 2014 [citado em 30 jan 2018]; 49(7):864-77. Disponível em: http://www.tandfonline.com/doi/abs/10.31 09/10826084.2014.880725?journalCode=isu $\mathrm{m} 20$

17. Borburema T, Pacheco A, Nunes A, Moré C, Krenkel S. Violência contra mulher em contexto de vulnerabilidade social na atenção primária: registro de violência em prontuários. Rev Bras Med Fam Comunidade [Internet]. 2017 [citado em 30 jan 2018]; 12(39):1-13. Disponível em: https://www.rbmfc.org.br/rbmfc/article /view/1460 
18. Stone AL, Becker LG, Huber AM, Catalano RF. Review of risk and protective factors of substance use and problem use in emerging adulthood. Addict Behav. [Internet]. 2012 [citado em 30 jan 2018]; 37(7):747-75. Disponível em: https://www.sciencedirect.com/science/arti cle/pii/S0306460312000810?via\%3Dihub https://doi.org/10.1016/j.addbeh.2012.02.0 14

19. Morais AC, Malfitano APS. O terapeuta ocupacional como executor de medidas socioeducativas em meio aberto: discursos na construção de uma prática. Cad Bras Ter Ocup.
2016 [citado em 30 jan 2018]; 24(3):531-42. Disponível em: http://www.cadernosdeterapiaocupacional.u fscar.br/index.php/cadernos/article/view/1 388

\section{CONTRIBUIÇÕES}

Andrea Ruzzi Pereira contribuiu na concepção e intervenções no estágio, na redação e, revisão. Larissa Nascimento Marques participou na concepção, intervenções no estágio e redação. Mariana Melo Parreira atuou na concepção, nas intervenções no estágio e redação.

\footnotetext{
Como citar este artigo (Vancouver)

Ruzzi-Pereira A, Marques LN, Parreira MM. A música como forma expressão da realidade de adolescentes em vulnerabilidade social. REFACS [Internet]. 2018 [citado em inserir dia, mês e ano de acesso]; 6(Supl. 2):662-668. Disponível em: inserir link de acesso. DOI: inserir link do DOI.

Como citar este artigo (ABNT)

RUZZI-PEREIRA, A.; MARQUES, L. N.; PARREIRA, M. M. A música como forma expressão da realidade de adolescentes em vulnerabilidade social. REFACS, Uberaba, MG, v. 6, supl. 2, p. 662-668, 2018. Disponível em: <inserir link de acesso>. Acesso em: inserir dia, mês e ano de acesso. DOI: inserir link do DOI.

Como citar este artigo (APA)

Ruzzi-Pereira, A., Marques, L. N. \& Parreira, M. M. (2018). A música como forma expressão da realidade de adolescentes em vulnerabilidade social. REFACS, 6(Supl. 2), 662-668. Recuperado em: inserir dia, mês e ano de acesso de inserir link de acesso. DOI: inserir link do DOI.
} 